Trabajos y Comunicaciones, 2da. Época, No 45, e034, marzo 2017. ISSN 2346-8971

Universidad Nacional de La Plata.

Facultad de Humanidades y Ciencias de la Educación.

Departamento de Historia

\title{
La "gran demora" en la Industria argentina: aproximaciones y perspectivas historiográficas sobre un debate inconcluso 1
}

\author{
The 'big delay' of the argentine industry: approaches and \\ historiographical perspectives about an unconcluded debate
}

\author{
Fabricio Salvatto * \\ * Universidad Nacional de La Plata , Argentina | salvattof.unlp@gmail.com
}

\section{PALABRAS CLAVE}

Gran demora

Discursos políticos

Debates historiográficos

Alejandro Bunge

KEYWORDS

Big delay

Political discourses

Historiographical debates

Alejandro Bunge

\section{RESUMEN}

Se estudia la noción de "gran demora" en la industria argentina a partir de su origen como problema de la agenda política abierta por Alejandro Bunge, a fines de la década de 1920 y su utilización en algunos enfoques historiográficos a partir de los años 60'. Se muestra que la aceptación o el rechazo de una "gran demora" resultó de los criterios de un "deber ser" del desarrollo industrial reconocible en los discursos políticos, económicos e historiográficos. Tanto Alejandro Bunge como algunos de sus comentaristas de la década del 60' se vieron cuestionados por estos enfoques que trataron de justificarlo o darle un nuevo fundamento epistemológico.

\section{ABSTRACT}

This article studies the "big delay" notion of the argentine's industry since its origin as a problem within a political agenda opened up by Alejandro Bunge in the late 20's until its utilization by some historiographical approaches in the 60's. The article demonstrates that the acceptation or rejection of a "big delay" came out from a "must be" criteria concerning the industrial development, recognizable in the political, economic and historiographical discourses. Both Alejandro Bunge and some of his commentators in the 60's, which tried to justify or provide new epistemological basis to Bunge's position, were questioned by new approaches. 


\section{I-Introducción}

El presente trabajo tiene por objetivo revisar la noción de "gran demora” en la industria argentina a partir de su origen como problema de la agenda política a fines de la década de 1920 y su utilización en algunos enfoques historiográficos que abordan este período. Algunos historiadores de la historia económica argentina del siglo XIX destacaron que el ingreso del país al mercado internacional se relacionó con una dependencia de éste, quedando indefectiblemente afectado por sus crisis y los vaivenes de la economía mundial. La Guerra de Crimea y la guerra franco-prusiana de las décadas de 1860 y 1870 fueron algunas de sus manifestaciones más evidentes y llamaron la

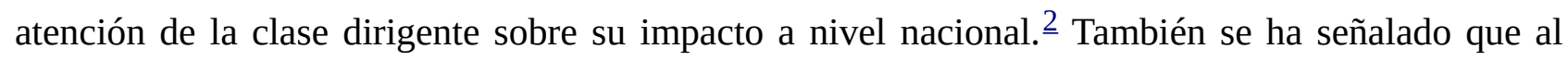
volver a la normalidad en los subsiguientes años de paz, los proyectos de industrialización propuestos en las últimas décadas del siglo XIX eran dejados a un lado por la dirigencia política para inclinarse hacia el viejo camino de crecimiento: la actividad agropecuaria para la exportación. Con la crisis de la bolsa en 1890 reaparecieron los proyectos para cambiar el modelo con la intención de resolver problemas relacionados con crédito internacional y la política financiera vigente.

Sin embargo, nuevamente quedaron truncos al salvaguardar la situación el propio mercado internacional en combinación con el nuevo escenario local: el precio del trigo y la expansión de este cereal en el campo argentino. Quienes auspiciaban una mayor autonomía promocionando un papel destacado a la industria nacional serían los mismos que a fin de siglo se presentaban como defensores del modelo basado en la exportación de productos primarios mediante el librecambio. Este problema plantea una cuestión interesante sobre el rol estatal en las políticas económicas como única vía del fomento de la industria antes y después de 1914.

Ya en el siglo XX, la Gran Guerra había mostrado algunos de los límites de este modelo al contraerse el comercio, lo que llevó a que aumentase el protagonismo de distintas ramas de la industria. Según algunos autores, el regreso a la normalidad hacia la década del 20', no fue un período de simple abandono y vuelta atrás al viejo modelo, como anteriormente había sucedido. Algunas voces comenzaban a reaccionar y alertaban sobre la necesidad de expandir ciertas industrias que habían mostrado claras señales de crecimiento. Estas voces tendrán, frente al panorama de la economía mundial, un discurso mejor articulado hacia finales de la década del 1920.

Alejandro Bunge selló una impronta en los debates sobre la política económica respecto a la necesidad de una industria propia y abrió la posibilidad -años más tarde- de realizar este objetivo con un programa de reformas preciso. Pero ésta impronta resurgió en el debate historiográfico a partir de los años 60', al punto de llegar a plantearse la aceptación de una "gran demora” o de rechazarla según los nuevos criterios del análisis histórico-económico.

\section{II- Perspectivas historiográficas sobre la industria y la manufactura en Argentina desde mediados del siglo XIX hasta 1930}

Existe un común acuerdo historiográfico en que la segunda mitad del siglo XIX argentino constituyó un período de grandes transformaciones políticas, económicas, sociales y culturales, sobre todo por la nueva articulación de la región con el mercado mundial (Bonaudo, 1999:13-14). En cuanto a las trasformaciones generales en la economía, historiadores como Cortes Conde y Roy 
Hora sostienen que las condiciones favorables respecto de las condiciones internacionales de este período no fueron acompañadas por un desarrollo institucional y político equivalentes.

Pese a las mutaciones en la demanda internacional de productos primarios, la influencia de mano de obra inmigrante, el desarrollo del transporte y de la infraestructura portuaria, el crecimiento urbano, la alfabetización y el aumento de la mano de obra calificada, etc., el país presentaría serios obstáculos para acompañar las transformaciones de la economía mundial en el corto plazo. Roy Hora señala algunas de las razones por las que, en los años finales del siglo XIX y principios del XX, se configuran los límites de la expansión económica de éste período: “...esta historia de crecimiento económico no incluyó a todos por igual. A lo largo del siglo XIX cobraron creciente relevancia dos obstáculos, uno regional y otro social, a la expansión del progreso social” (Hora, 2010:260). Las diferencias entre la zona litoral y resto del país, así como las desigualdades entre los sectores altos y medios de base rural y los trabajadores asalariados crearon una organización social capaz de sostener el modelo económico finisecular hasta 1914:

"El estallido de la Gran Guerra trajo consigo una violenta alteración de la economía mundial que tanto había favorecido al país. El conflicto marcó el fin de una fase secular de crecimiento que, con todas sus limitaciones, hizo posible un muy sensible proceso económico y social. A partir de este momento, cada paso hacia adelante resultó más lento y trabajoso. La expansión recomenzó una vez culminada la Primera Guerra, pero desde entonces la Argentina encontró cada vez más dificultades para igualar los formidables éxitos del siglo previo. Hasta cierto punto, ello era inevitable.” (Hora, 2010:263)

Si bien el citado trabajo de Roy Hora no aborda el período siguiente a la Paz de Versalles y los efectos de la economía mundial de entreguerras en Argentina, en esta última oración se menciona un problema presente en la historiografía que luego revisaremos. Se trata de los enfoques teleológicos o del posibilismo histórico: Los "que hubiera pasado si...” o "que posibilidades hubo y que se terminó haciendo" para explicar el "fracaso", el atraso y "la argentina que no fue”. Si hay una "argentina que no fue”, es que hay -en cierto sentido- una argentina que “debería haber sido" pero que no existe. $\underline{3}$ Esta tensión se identifica con la problemática de la "gran demora” y, tanto Alejandro Bunge como algunos de sus comentaristas de la década del 60’, se vieron cuestionados por estos enfoques y trataron de justificarlo o darle un nuevo fundamento epistemológico.

Sin embargo, la obsesión por el origen de este problema estructural, probablemente inevitable como dice Roy Hora, pueda rastrearse mucho más atrás, antes incluso de la consolidación del estado nacional, cuando los frutos de la economía pampeana se combinaron con importantes innovaciones y avances tecnológicos y la incorporación de las colonias agrícolas entre los años 60’ y 80’ del siglo XIX.

José Carlos Chiaramonte (1971) ha mostrado en Nacionalismo y Liberalismo económicos en Argentina (1860-1880) que a pesar de la expansión económica producida principalmente por la producción vinculada al ámbito rural, este modelo fue puesto en cuestión frente a las dificultades financieras generadas a partir de problemas externos. ${ }^{4}$ Las crisis de los años $60^{\prime}$ y $70^{\prime}$ tuvieron como correlato diversos proyectos que Chiaramonte llama "génesis de las tendencias 
industrialistas” (1971:75). Es sobre la base de estas crisis que se planteará modificar aquellas tendencias vigentes a partir de las intervenciones proteccionistas referenciadas como políticas “nacionalistas”. Aunque para el autor las tendencias proteccionistas están presentes en diversos momentos de la historia argentina, en la década del 60' se plantea por primera vez una instancia más comprometida que el mero gravamen de aranceles comerciales, entre las cuales se podía contar -por ejemplo- el desarrollo de la producción de manufactura nacional en remplazo de las europeas. La crítica del liberalismo económico, los beneficios que podría significar una diversificación de la producción en el largo plazo y el desarrollo de una incipiente industria textil, fueron algunas de las señales del cuestionamiento de los contemporáneos al modelo imperante. Sin embargo, estas críticas tuvieron algunos límites, puesto que el proteccionismo y el "aislamiento" sonaban a rosismo, un recuerdo aún fresco en las posturas más liberales de la época (Chiaramonte, 1971:72).

Entre las iniciativas más importantes puede contarse la fundación de la Fábrica de Paños como una sociedad anónima, promovida por la Sociedad Rural Argentina, para la industrialización de la lana producto sensible a las oscilaciones del mercado internacional. Chiaramonte señala que

"Las tendencias industriales surgidas en la Sociedad Rural Argentina son llevadas a su expresión más clara por Eduardo Olivera y Ezequiel N. Paz. Y aunque no se pronuncien abiertamente por el proteccionismo [...] y hasta lo ataquen expresamente, como en el caso de Paz, sus formulaciones contienen ya varios de los objetivos principales del grupo proteccionista de Vicente. F. López, entre ellos el de emancipar al país del carácter de mero proveedor de materias primas para el mercado extranjero.” (Chiaramonte, 1971:75)

El fracaso del proyecto de la Fábrica de Paños así como también de las tendencias proteccionistas más generales se debió a varios motivos. En primer lugar, los primeros signos de recuperación europea a principios de los años 70’ revirtieron la mala mirada en el librecambio. En segundo lugar, el auge de la producción lanar mostraba ciertos límites en el ámbito nacional a finales de esta década. En tercero, la mantención de la primera fábrica textil dependía de un estimulo estatal que resultó insuficiente. Por otra parte, el libre cambio garantizaba al litoral el predominio del interior -aspecto que señala también Roy Hora- acentuado a partir de la introducción del ferrocarril y desapareciendo, de este modo, las distancias naturales que habían posibilitado la supervivencia de los mercados de las provincias del interior.

En el año 1873 los efectos de la nueva la crisis repercutieron fuertemente en la producción lanera pero más aun en el comercio y las finanzas. Sin embargo, el factor desencadenante fue similar a la crisis de 1866: "la caída de los precios de los productos argentinos en los mercados internacionales" (Chiaramonte, 1971:97). En los Anales de la Sociedad Rural Argentina aparecen voces como las de Ezequiel N. Paz, que en 1871 plantean un abandono de las tradicionales inversiones en el ámbito rural por la canalización de los beneficios hacia la industria. No obstante, -dice Chiaramonte- estas advertencias llegaron tarde, puesto que la recuperación de los productos argentinos en 1874 se tradujo en una recuperación en la confianza en los mercados internacionales y en el librecambio. Sin embargo, en los años subsiguientes siguieron apareciendo debates en torno al problema del proteccionismo de la industria naciente en voces como las de Vicente Fidel López (1873 y 1874) y Carlos Pellegrini (1875 y 1876). 
Los estímulos para la industria que se llevaron adelante en este período tuvieron como principal instrumento los gravámenes aduaneros a partir de la Ley de Aduana de 1876 y sus reglamentaciones posteriores de 1883 y 1887 (Gallo; Cortes Conde, 1995:33). Ezequiel Gallo señala que para los industriales de aquella época las disposiciones de la Ley de Aduana de 1876 no favorecían en absoluto el crecimiento de la industria, puesto que algunas materias primas necesarias para la manufactura como el zinc, la hojalata y el bronce, pagaban los mismos derechos que los productos elaborados. Gallo hace hincapié en este sentido - como Chiaramonte- en el rol de boom exportador, la “manía ferroviaria” y sus consecuencias con respecto a las industrias locales:

“... la expansión de la economía exportadora ocasionó al mismo tiempo trastornos insalvables a los sectores más tradicionales de la industria local. El ferrocarril, por ejemplo provocó la desintegración de las industrias artesanales del Interior, y muy especialmente de las añejas tejedurías. Estas artesanías, basadas por lo general en productores individuales, pudieron subsistir mientras los altos costos del transporte terrestre las protegieron de la competencia extranjera, pero el tendido ferroviario modificó sustancialmente la situación, y la invasión de textiles europeos de más bajos costos eliminó a los más ineficientes productores nativos”. (Gallo; Cortes Conde, 1995:34)

El acento se pone fundamentalmente en el impacto del ferrocarril sobre las economías del interior y rara vez ofrecen una explicación de las condiciones que posibilitaron la recepción de esta demanda. El ferrocarril parece tener un efecto axiomático sobre las economías, allí donde penetra con una nula o escasa resistencia.

La crisis de 1890 fue generada principalmente por la especulación financiera, y sin alcanzar los niveles de la de 1929, fue más brusca que la de 1873. Pero la recuperación fue aun más rápida por las excelentes cosechas de 1891 y las de los años subsiguientes. Habíamos dicho más arriba que Vicente Fidel López y Carlos Pellegrini se pronunciaban por el proteccionismo y el fomento de la industria 1876. Bajo el programa del Partido Autonomista Nacional, éstos expresaban en 1878 promover las industrias de la Nación “...que la emanciparán del dominio económico del extranjero, arrancándola además de la postración en que ha caído.” (Chiramonte, 1971: 262). Sin embargo, la extraordinaria expansión económica de los años 80’ y la pronta recuperación de la crisis financiera de principios de los años 90' inclinaron a Pellegrini y a López (Presidente y Ministro de Hacienda correspondientemente) a continuar la política comercial favorable a las exportaciones agropecuarias bajo los viejos parámetros liberales. (Gallo; Cortes Conde, 1995:48-49)

Respecto de la relación entre industria, la expansión agraria y el proteccionismo, el trabajo de Fernando Rocchi (1998) nos brinda un amplio análisis sobre las complejas relaciones en la política industrial del orden conservador y su continuidad en las presidencias radicales. A partir de una variedad de fuentes testimoniales como diarios y debates parlamentarios, Rocchi muestra la presencia de posturas proteccionistas y a favor de una política industrial desde los años 70’́del siglo XIX. El librecambismo convivió con una crítica permanente en proyectos alternativos como los de Tagle y Anadón en los últimos años del siglo. Figuras políticas como Carlos Pellegrini combatieron estos proyectos en el ámbito del senado. Por otra parte, la presencia de una permanente mayoría librecambista en la Cámara de Diputados constituyó algunos de los ejemplos de las complejas 
relaciones entre el poder político y la economía a fin de siglo. Las diferentes variables de la cual dependen las políticas industriales y su acogida en la sociedad argentina muestran un panorama aun más complejo del que había intentado esbozar Ezequiel Gallo:

“El orden conservador -dice Rocchi- tuvo, en síntesis, un acercamiento hacia la industria que una explicación estructural (e inclusive demasiado estructurada) no puede describir de manera satisfactoria. El entramado que Ezequiel Gallo en 1970 encontraba complicado, terminó siendo caótico”. (Rocchi, 1998:129)

No obstante, estas políticas de librecambio y el fomento de ciertas industrias no fueron totalmente incompatibles como se ha insinuado, ni el vínculo entre desarrollo industrial y proteccionismo fue tan mecánico. Ezequiel Gallo señala que si bien en 1920 Argentina estaba lejos de ser un país industrializado, la industria fue progresando desde 1880 alcanzando -en ciertos momentos- un ritmo espectacular pero esto se debió, principalmente a la expansión agraria de este período (Gallo, 1998:15). Por otra parte, Gallo considera que si se observan las cifras de crecimiento no se evidencia necesariamente una relación conflictiva entre la industria y el sector agrícola, sino que este conflicto se verifica a partir de las políticas arancelarias desde la etapa finisecular que más arriba señalamos.

En esta línea, Fernando Rocchi destaca que el mercado interno se expandió entre 1877 y 1910 a partir del boom exportador y que por su parte los logros de la industria fueron notables: Hacia 1910 esta producción industrial

“...cubría un abanico bastante amplio de bienes de consumo que, sin hacer de la Argentina un país industrializado, le daban a la actividad fabril una participación en el producto bruto interno mayor que la del sector agrícola o ganadero por separados. Junto con este aumento cuantitativo, la industria sufrió cambios cualitativos profundos, entre los que sobresalió una producción en serie realizada en grandes empresas.” (Rocchi, 1998:552).

Asimismo, Ezequiel Gallo señala que pese a los conflictos que surgen de los intereses de diversos sectores de la economía, como ser entre el sector agrícola e industrial, "las tensiones y conflictos se desplegaban dentro de un sólido marco de consenso generado por la gran expansión económica” (Gallo, 1998:24).

Por su parte, Cortes Conde ha indicado que, en este período (1895-1914), la especialización agropecuaria no necesariamente había determinado una falta de asignación de capital al sector de las industrias: "En realidad, -dice el autor- la industria apareció, en cierto modo, como una prolongación de la actividad (saladeros, frigoríficos, molinos de harina, fabricas de vino) el que tuvo fuertes capitales” (Cortes Conde, 1973:66). Cortes Conde señala que cuando algunos estudios argumentaron la falta de inversión de capital a la industria es porque éstos se han basado en censos de pequeños talleres cuyo principal problema fue la escasez de capital.

Un trabajo de Jorge Sábato (1991) sobre la clase dominante en la Argentina moderna nos da la posibilidad de encontrar algunas de las problemáticas en tensión con los estudios hasta ahora nombrados. Tiene que ver - como ha dicho Rocchi (1998:103)- con “...la existencia de un 
empresariado multiplanteado como alternativa a la visión tradicional de los sectores en pugna con intereses económicos diferentes”.

Jorge Sábato realiza una caracterización de la clase dominante que habría formado y consolidado en el último tercio del siglo XIX. A fin de no repetir todos los ítems señalados por Sábato citamos solo algunos:

"Esta clase (...) poseía buena parte de la tierra, actuaba en una variada gama de actividades y su principal base de poder económico- social residía, sobre todo, en el control del comercio y las finanzas; [...] La clase estaría muy poco fraccionada internamente, a diferencia de lo que hubiese ocurrido si distintos grupos se hubieran implantado y controlaran preferentemente actividades económicas distintas (industriales, agrícolas, ganaderas, etc.);” (Sábato, 1991:109-110).

Esto les habría permitido como clase

“...implementarse simultáneamente en una serie de actividades productivas y especulativas (desde la producción agropecuaria hasta la industrial [...] infraestructura, especulación urbana y rural, etc.) [...] El conjunto de los propietarios presentaría un grado relativamente bajo de diferenciación interna en términos de comportamiento y de implementación multisectorial.”

Sin embargo, -dice Sábato- esto no implicaba que cada individuo permaneciera estable sino que también se producía cierta movilidad vertical a la vez que redefinía a la propia clase, los poderes de esta y cómo se ubicaban y reubicaban dentro de la clase. Esta descripción general de Sábato permite comprender algunas de las relaciones entre las políticas industriales del período y la dificultad señalada por Rocchi al intentarse hacer una mirada de conjunto que resulte satisfactoria.

Carlos Díaz Alejandro se ocupó de señalar que el crecimiento de las exportaciones entre principios de siglo y 1929 fue el principal responsable del crecimiento industrial haciendo cierto hincapié, como veremos luego, en la vinculación señalada entre la actividad agropecuaria y la industrial . Aníbal Jáuregui (1993), por su parte, considera que la dependencia de los industriales del sector agropecuario “...no significaba un mímesis. Los industriales fueron desarrollando un sentimiento de identidad que se fundaba primero en las diferentes funciones dentro del sistema económico, pero también en sus características constitutivas” (Jáuregui, 1993:162). Por otra parte, no se niegan las cuestiones generales abordadas por Sábato puesto que en su análisis Jáuregui complejiza el problema al relacionar las alianzas de la élite conservadores y el gobierno -con el poder del Estadoen los años 20’ y 30’, frente al movimiento huelguístico y las manifestaciones obreras. Para el autor, la participación de la Unión Industrial Argentina no era débil, ni era un subsector de la clase dirigente, sino más bien

“...un sector social en ascenso de las clases dirigentes en manos de las élites tradicionales. Los industriales solían presentar sus diferencias con el sector terrateniente exportador en forma larvada, en virtud de su dependencia estructural hacia aquel”. Tal vez- dice el autor- de no mediar la Gran Depresión que ampliaría los canales vinculantes entre ambas partes, los enfrentamientos entre industriales y terratenientes habrían sido más abiertos” (Jáuregui, 1993:190). 
Dicho de otro modo, la Gran Depresión sucedió y por lo tanto condujo a ésta heterogénea clase dominante a un posible comportamiento tradicional esbozado por Jorge Sábato.

Para abordar la discusión que sigue es necesario tener en cuenta que al margen de los pormenores discutidos hay un cierto acuerdo en los autores citados en que hasta 1914-1919 la actividad industrial fue activa en combinación con la expansión económica que provenía de las últimas décadas del siglo XIX. La idea de una "gran demora” entre los años 1914 y 1930 inaugurada por Alejandro Bunge sostiene la existencia de un crecimiento industrial en Argentina, por lo menos hasta la época de la Gran Guerra, y puede extenderse este crecimiento hasta 1930 si tenemos en cuenta lo planteado por Díaz Alejandro. No queremos decir, entiéndase bien, que los autores citados apoyan cabalmente los discursos de Bunge sino, simplemente que los estudios de las últimas décadas del siglo XX observan algunas señales de estancamiento entre 1914 y 1930. Algunos lo ven en la conformación de la clase dominante, otros en los índices de crecimiento industrial a partir de la expansión agraria, etc. Sin embargo, otros al discutir la inexistencia de una gran demora señalan un crecimiento industrial durante la década de 1920.

\section{III- El origen del discurso y sus perspectivas historiográficas.}

El problema en torno al lugar del progreso de la actividad industrial en la Argentina en el período anterior al año 1935 es muy difícil de determinar por la falta de datos, censos completos e integrales y estadísticas que corroboren los testimonios y las consideraciones de diversos referentes contemporáneos. Esto es sostenido por Adolfo Dorfman (1970) al señalar que: "Ninguna afirmación segura puede adelantarse respecto al progreso realizado por la industria argentina en su conjunto con anterioridad a 1934-35 (año en que se levanta el Censo Industrial)” (Dorfman, 1970:381). De este modo según Dorfman “...los cálculos existentes adolecen de deficiencias de información, que las invalidan para extraer de ellas conclusiones generales” (Ibídem). Los datos extraídos de la Dirección de Comercio y de la División Estadística del Departamento Nacional del Trabajo, resultan valiosos -dice el autor- pero serían fragmentarios y basados sobre todo en los establecimientos de la Capital Federal. Es probable que la crítica de Dorfman se dirija a los abordajes de estudios que intentan explicar los “problemas del crecimiento industrial” entre 1895 y 1914 a partir de algunos índices y estadísticas para la capital y el litoral. La variedad de fuentes que Cortes Conde utiliza refuerza la idea de Dorfman sobre la fragmentariedad de la información disponible, pero por otra parte las conclusiones de Cortes Conde no apuntan necesariamente a un plano general del progreso de crecimiento industrial sino a describir los cambios producidos en este sector entre 1895 y 1914, así como la nueva reubicación de ciertos establecimientos entre la ciudad de Buenos Aires y la provincia. También Gallo utiliza estos datos para una mirada del desarrollo industrial para el período anterior a 1930. Por su parte, Díaz Alejandro al analizar los comportamientos de los aranceles aduaneros se referencia en la información previa a la década de 1930 (utilizando los anuarios de la Dirección General de Estadísticas) y en cifras posteriores como las brindadas por la CEPAL. (Díaz Alejandro, 1975:282, 290, 293)

En este cuadro de situación, y teniendo en cuenta los debates sobre las conclusiones del progreso industrial y su relación con la existencia o no de un demora en la industria desde 1914, el eje de la 
discusión posible termina centrándose en las consideraciones de los actores políticos y cómo estas fueron revisadas posteriormente. Vale decir, ante la imposibilidad de plantear una respuesta basadas en datos consensuados, la cuestión sobre la "gran demora” termina volcándose en la percepción de los contemporáneos y en el análisis de este discurso por la historiografía. Como se puede apreciar en el apartado anterior, la mayor parte del análisis por parte de los autores citados se basa en discursos parlamentarios, notas de prensa, discursos políticos y algunas estadísticas insuficientes de acuerdo con Dorfman- como para brindar un panorama general. Por consiguiente, analizaremos cómo se inició el debate.

Carlos Díaz Alejando le ha adjudicado a Alejandro Bunge el ser uno de los observadores más perspicaces de su época al darse cuenta, ya 1923, de las consecuencias del proteccionismo agrícola norteamericano y el británico, apelando este último a sus recursos coloniales en el sostenimiento del régimen imperial (Díaz Alejandro, 1975:294). Pero incluso antes, en una conferencia dictada en 1921 Bunge decía:

“Todos sabemos que Inglaterra realiza grandes esfuerzos por obtener sus alimentos, protegiendo la producción en sus dominios. [...] La producción argentina podrá ser sustituida en pocos años por la de los dominios. Y vendiendo los dominios estos grandes cargamentos de productos a la metrópoli, estarán en condiciones de adquirir en ella mayor cantidad de artículos manufacturados que hasta hoy, con lo cual llenarán satisfactoriamente las necesidades de exportación industrial de Inglaterra.” (Halperín Donghi, 2005:527)

Bunge señala que esta situación dejaría al país fuera de la órbita comercial o, en todo caso, con una vinculación menor. Pero esta circunstancia coincidía con "la necesidad y la posibilidad (...) de una vida económica más independiente.” (Ibídem). Asimismo, Bunge reconocía que en la Argentina se habían alzado voces a favor de este ideal de independencia en el terreno de las ideas, pero que ahora la tarea que quedaba por delante no era la reacción sino la síntesis. Dicho de este modo la propuesta aun permanecía dentro del terreno de las ideas.

Luego de una estancia en San Pablo, Bunge manifestó su preocupación por las diferencias en materia de política económica entre la Argentina y Brasil, pues estaba muy impresionado con el país vecino por sus trayectos y transformaciones desde fines de la primera década del siglo XX. Allí señala que “....asomado a un balcón del Explanada Hotel de San Pablo, creí encontrarme en alguna ciudad europea o norteamericana.” (Halperín Donghi, 2005:525). Parecía encontrarse -dice- “...en el Palace Hotel de Boston, o del kaiserhof de Berlín. Tuve la impresión de estar soñando; aquello no parecía un ciudad sudamericana.” (Ibídem). Según Bunge, el progreso de San Pablo, como el de otras ciudades brasileras, radicaba en que Brasil no era exclusivamente un mero productor y exportador de monocultivos como el café, sino que había hecho un esfuerzo por estimular y fortalecer su crecimiento industrial:

“Todo lo que hemos soñado y queremos en nuestro país en materia de política económica estaba allí practicándose de lleno y dando frutos excelentes: fomento y defensa de los nuevos cultivos, desarrollo de la manufacturas, cooperación con los comercios, estimulo al trabajo nacional. ¡A qué altura habría llegado hoy la Argentina si hubiera practicado una política semejante a la de Brasil desde 1911!” (Halperín Donghi, 
2005:526). $\underline{5}$

No pretendemos con estas citas poner en el mismo plano lo que Bunge planteaba entonces con lo que dirán algunos autores sobre Bunge, sino que queremos destacar las tempranas reflexiones sobre los problemas en las políticas económicas en la Argentina a fin de poner en perspectivas los elementos con los que habría podido fundamentar la idea de una gran demora desde 1914. Estas reflexiones del autor datan de 1921-1923, pero probablemente cobraron mayor difusión en 1928 -y en los años subsiguientes- con la publicación de los volúmenes de La economía argentina, en donde el autor recopila notas, artículos y conferencias.

Díaz Alejandro plantea que aquel razonamiento de Bunge respecto a las necesidades del proteccionismo y de una señal de cambio del modelo imperante, era respetable pero no concluyente. El motivo se reconoce en que Díaz Alejandro vincula el diagnostico de Bunge con la crisis del 1929-1932, señalando que fueron las condiciones flexibles de la economía argentina lo que permitió amortiguar los efectos de la crisis mejor que otras naciones (Díaz Alejandro, 1975: 294-295). Sobre este punto debemos señalar dos aspectos importantes: en primer lugar, Díaz Alejandro responde a las observaciones de Bunge -hechas en los primeros años de la década del 20'- con consideraciones fácticas posteriores, con el balance de los acontecimientos que constituyen la llegada de la crisis y la superación de esta en el corto plazo, a partir de la política económica llevada adelante por entonces. En segundo lugar, puede desprenderse de aquí una de las críticas sobre de los criterios de validación que apoyan o desestiman los pronósticos de Bunge señalados por varios autores: la observación, la reflexión, el discurso y la comparación. $\underline{6}$ Criterios que Díaz Alejandro considera “no concluyentes”, pero que también son revisados por Di Tella y Zymelman y Llach (1985).

Estos autores, parten de la apreciación del valor testimonial de Bunge al tratar de hacer un diagnóstico correcto sobre la falta de una política de industrialización antes de 1930. Algunos de los ensayos de Bunge son más declarativos que analíticos. Por ejemplo: “El 25 de mayo de 1810 pronunciamos el grito de la patria que nos dio la libertad política. Ha llegado la hora de dar el grito del trabajo nacional que ha de traernos la autonomía económica” (Halperín Donghi, 2005:531). Sin embargo, los autores arriba citados discuten la idea de una gran demora tratando de señalar la limitación del análisis de Bunge o de encontrar una teoría o marco científico que le otorgue criterios de validación a sus dichos. Al respecto Llach llama la atención “...sobre los peligros de enfocar el tema del desarrollo económico argentino desde una perspectiva idealista, poniendo un énfasis exagerado en sus eventuales 'desvíos' con respecto a un sendero ideal de crecimiento o a 10 ocurrido en otros países.” (Llach, 1985:33)

Pero por otra parte dice Llach “...O'Connell (1984) se empeña en destacar que si algún sector de la sociedad percibió que estaban cambiando las ventajas comparativas y que era inconveniente especializarse en demasía a la luz de las tendencias restrictivas del comercio mundial, no pueden tildarse de ‘idealistas’ sus planteos” (Ibídem).

Juan Carlos Korol e Hilda Sábato han señalado que "Más allá del análisis precursor de Bunge, sería la crisis de 1930 la que estimularía a políticos y ensayistas a incorporar de lleno la cuestión del desarrollo industrial del país a la agenda de discusión.” (Korol; Hilda Sábato, 1997:11-12) De este modo, en la década del cincuenta comenzaron a surgir organismos del Estado, asociaciones 
corporativas y grupos de interés que buscaban respuestas al fracaso de la industrialización, así como ensayistas y pensadores que trataban de explicar la decadencia argentina a partir de la década del 30’. En esta línea se centraría, Díaz Alejandro en la década del 60’. Pero fueron Di Tella y Zymelman quienes rescataron la idea de la gran demora que cuajó en un nuevo debate. Como señala Llach, estos

“...replantearon, con renovados fundamentos teóricos y empíricos, que el desarrollo económico argentino había sufrido una demora después de la Primera Guerra, se abrió una interesante polémica a la que contribuyeron, entre otros, autores como Gallo, Díaz Alejandro, Geller, Vázquez Presedo, Cortes Conde y O' Connell” (Llach, 1985:28).

Di Tella y Zymelman, considerando una mirada amplia a la historia económica argentina, señalaron que hacia 1914 era necesario un cambio de dirección que no fue llevado a cabo. Este cambio consistía en que la tasa de crecimiento favorable hasta ese momento comenzó a mostrar señales de debilidad, como la finalización del ciclo de expansión agrícola en la frontera pampeana (Gallo, 1998:14). El sesgo anti-industrial de la época fue responsable de que no se observara la necesidad de volcarse al sector industrial, "por este motivo -dice Gallo- los autores han denominado a este período como el de la 'gran demora”” (Ibídem). Aldo Ferrer llegaría a conclusiones similares basándose en otras premisas metodológicas, señalando que los grandes latifundistas contribuyeron a obstaculizar los impulsos necesarios para la industrialización "cuando los circunstancias así lo demandaban” (Ibídem). Más allá de las citadas diferencias metodológicas, tanto en Di Tella y Zymelman como en Ferrer los problemas del estancamiento económico comenzarán en 1914 con la desaceleración del crecimiento y se consolidarán con la crisis de 1929.

Como se señalo más arriba, las observaciones y reflexiones de Bunge fueron retomadas por Di Tella y Zymelman con renovados fundamentos teóricos y empíricos. Estos se basaron en el modelo de etapas del esquema de Rostow para analizarlo en el plano de la economía argentina. Como dice Díaz Alejandro, estos autores sostuvieron la idea de que “...el lapso que va de 1914 a 1933 constituye una 'gran demora', situada entre las 'condiciones previas' (1880-1914) y el 'despegue' (1933-52)”, siendo el período 1914-1929 una oportunidad desperdiciada por la política económica (Díaz Alejandro, 1975: 357). $\underline{7}^{-}$

La crítica de Díaz Alejandro a la tesis de estos autores, como o otros que por distintos motivos consideran una demora (1914-1933), puede sostenerse en que el autor plantea una valoración distinta a este período, puesto que para él las circunstancias externas, tales como escaso crecimiento económico británico obstruyeron el crecimiento argentino, como sucedió también con Canadá y Australia. ${ }^{8}$ La respuesta del país ante este problema externo fueron las que eran posibles de ser llevadas adelante. La pregunta del autor sería: ¿Por qué en respuesta a la situación internacional se confiaría en el estímulo al sector industrial (por ejemplo en 1925) cuando la actividad agropecuaria era próspera en aquel momento? (Díaz Alejandro, 1975:360) Díaz Alejandro dice así que “...a menos que se sostenga que las autoridades argentinas hubieran debido prever la Gran Depresión, o que debieran haber recurrido a políticas keynesianas en el lapso 1914-17, la tesis de la 'gran demora' resulta insostenible” (Ibídem). La crítica no parece estar dirigida principalmente a Bunge sino al trabajo de Di Tella y Zymelman. 
Díaz Alejandro en el prefacio de Ensayos sobre la historia económica argentina advierte sobre los “prósperos años que precedieron a 1930” y más adelante da cuenta de que es desde esta época en que comienzan los problemas de estancamiento. Según Rocchi, los análisis de Díaz Alejandro tienen un sesgo ideológico a favor de la economía abierta y plantea que sus consideraciones sobre la epata anterior y posterior a 1930 tienen su base en los problemas del estado intervencionista de mediados de los años 60’ (Rocchi, 1998:102).

Llach ha sintetizado gran parte de este debate como hemos señalado en varias citas. Pero para la época en que Llach publicaba su trabajo (1985) este debate estaba lejos de cerrase (como el mismo autor señala). Otros de los aporte de este autor, que destacamos, tiene que ver con las diversas variantes que incorpora al problema. Por ejemplo el rol y el acompañamiento de la sociedad civil en los planes de reformas y en los proyectos de política económica. No es que ninguno de los autores citados no lo hayan tenido en cuenta, sino que Llach lo analiza específicamente con respecto al Plan Pinedo y otros proyectos políticos como los que predominaron durante el primer peronismo. Díaz Alejandro había planteado que “...si la reforma social no va acompañada de eficaces políticas económicas, al menos en las sociedades mixtas, suelen resultar muy efímeras” (Diaz Alejandro, 1975:13).

Por su parte Gerchunoff y Fajgelbaum señalan la presencia de una “demora social argentina”. Sin despejar todas las dudas al respecto dicen:

"La democracia parlamentaria australiana probablemente haya colaborado para que las preferencias colectivas pudieran reflejarse en la acción de gobierno, mientras que el régimen conservador argentino todavía no necesitaba la validación de su liderazgo en las urnas a través del ejercicio pleno del voto. A su vez, el parlamentarismo australiano, sin partidos dominantes, obligaría siempre a la construcción de consenso" (Gerchunoff y Fajgelbaum, 2016:54) $\underline{9}$

Por consiguiente, para los autores la “demora” es producto de una combinación entre una dinámica económica ventajosa -en el corto plazo-, la falta de desarrollo institucional y, fundamentalmente, un problema político. La comparación con Australia les permitió a los autores observar un modelo para explicar que elementos estuvieron ausentes en la Argentina de finales del siglo XIX y principios del XX.

Llach considera fundamental la posibilidad de que la clase dirigente lleve adelante las políticas económicas con un necesario consenso social. El autor aclara que los éxitos o fracasos no dependen exclusivamente de un modelo o programa de reformas y de sus problemas, como podría ser el Plan Pinedo, sino que el acompañamiento de la sociedad civil y la legitimidad constituyen gran parte de la responsabilidad en la imposibilidad del régimen político de turno para dar una respuesta satisfactoria a los problemas de estancamiento económico. $\stackrel{10}{ }$ Para Llach el problema de la demora se plantea en los términos de la discusión entre los autores citados, pero, por otra parte, asume la idea de una demora no solo por el hecho de que el debate estaba instalado en la agenda pública de los contemporáneos, sino a partir del reconocimiento oficial del problema por parte del equipo de Pinedo. Así, dice el autor: 
"Una sociedad de base eminentemente rentística como la Argentina en 1918, acostumbrada desde 1880 a un crecimiento rápido y que tendía a identificar a dicho crecimiento con un determinado modelo de desarrollo, percibirá las sucesivas crisis como meros 'accidentes' y cada recuperación como un 'retorno a la normalidad'. Recién en 1940, por obra de Pinedo y su equipo, se reconocerá oficialmente la necesidad de modificar la estrategia vigente. Habían pasado 22 años.” (Llach, 1985:37)

Con esta consideración Llach asume que el cambio de modelo debía sobrevenir, por lo menos, desde finales de la Gran Guerra. Bunge podía haber denunciado y recomendado políticas discutibles sobre una gran demora en la industria argentina como señalaban Di Tella, Zilberman y luego Díaz Alejandro, pero para Llach es bajo la intervención de Pinedo cuando se comienza a implementar una política estatal capaz de superar un modelo de desarrollo que venía reproduciéndose desde finales del siglo XIX y que en las segunda década del siglo XX mostraba un evidente estancamiento.

\section{IV- Palabras finales}

Hemos querido sintetizar algunos aspectos que constituyen el debate en torno a una "gran demora" entre 1914 y 1933 en algunos historiadores destacados en torno al tema. Para ello señalamos los análisis sobre el período de 1860-1914 y que abordan problemáticas similares, tales como rastrear el origen del estancamiento de la economía argentina. Este podía deberse a varios factores: un desfasaje entre una economía abierta y pujante, frente a una sociedad política que no acompañó este proceso; la falta de una política proteccionista; supuestos enfrentamientos entre el sector agropecuario y el industrial en el que el segundo fue vencido, etc. Luego revisamos las críticas a estos planteos como las realizadas por autores como Cortes Conde, Gallo, Rocchi y Gerchunoff. Abordamos brevemente los ensayos de Bunge, una de las voces de aquellos contemporáneos que denunciaba tempranamente (1921) los problemas del modelo económico vigente a partir de sus observaciones, aunque estas se relacionaban más bien con el proteccionismo. Estas consideraciones fueron retomadas dentro de la discusión académica con otros abordajes metodológicos como los de Di Tella y Zymelman, Díaz Alejandro y Llach, a quienes citamos mayormente. Con estos aportes hemos querido señalar la dificultad de poder analizar el ámbito de los discursos políticos y compararlos fehacientemente con datos consensuados sobre el grado de desarrollo industrial para los períodos anteriores a la década de 1930. Pensamos que el problema de contestar por la existencia o ausencia de una gran de demora parió de una necesidad de instalar un debate político (Bunge), y su continuación fue un esfuerzo de remplazar aquel debate con metodologías específicas del debate histórico para ubicar esta demora antes, durante o después de determinado período. Así, Di Tella y Zymelman -apoyados en Rostow- consideran la gran demora en la etapa esbozada por Bunge. Díaz Alejandro basándose en las bondades de la economía abierta cuestiona esta mirada señalando a la etapa anterior a 1930 como un período de expansión por el acierto (no siempre planeado) de la política económica de entonces. Llach, por su parte, propone unas líneas de análisis para complejizar y continuar este debate. Pensamos que es necesario revisar estas cuestiones porque constituyen un tema que problematiza los abordajes metodológicos, históricos, discusivos, y que por otra parte puede contribuir a que la historiografía constituya marcos de acuerdo sobre este tema a fin de superar los aportes realizados en las últimas décadas del siglo pasado. 


\section{Notas}

1 Agradezco los comentarios críticos sobre este trabajo al Dr. Andrés Regalsky en el marco del seminario "La industrialización argentina en el siglo XX. Una perspectiva histórica” (UNFREF, 2011)

$\underline{2}$ En relación con este problema de los vaivenes de la economía argentina a partir de 1866, pueden señalarse el fin de la guerra de secesión norteamericana (1861-1865), pues contribuyó a crear un boom artificial del precio de la lana que Argentina aprovechó. En cuanto a la crisis del 73 -que fue más una crisis general y menos sectorial que la del 66- se la asocia con la caída de la bolsa de Viena, después del entusiasmo que generó la victoria prusiana de 1870 y sobre todo por expectativas optimistas malogradas de expansión económica alemana. Por otra parte debe destacarse que en 1866 cayó la banca inglesa Overend, Gurney \& Company que estaba involucrada en el comercio de algodón con el lejano oriente.

$\underline{3}$ En este sentido, Pablo Gerchunoff y Pablo Fajgelbaum (2006) plantearon una pregunta con fuerte impacto editorial: "Por qué Argentina no fue Australia”, recientemente reeditado con el subtitulo “historia de una obsesión por lo que no fuimos, ni somos, pero... ¿̇seremos? (2016)

4 Véase en Chiaramonte (1971) págs.61, 64, 94-97, 112-113

$\underline{5}$ En las fuentes recopiladas en este trabajo pueden encontrar más ejemplos. Véase por ejemplo las págs. 529-531.

$\underline{6}$ En otras conferencias realiza una comparación con Estados Unidos y Canadá. Véase Halperín Donghi. Vida y Muerte de la República verdadera... Ob. Cit. Pág. 529

7 Véase también en Llach, 1985: 31 -32

$\underline{8}$ En una trabajo más reciente, al comparar Argentina con Australia, Gerchunoff y Fajgelbaum admiten la existencia de una "demora” que era fácilmente explicable por distintas circunstancias, entre ellas la falta de instituciones sociales y la dinámica económica antes y después de la crisis de 1890 (Gerchunoff y Fajgelbaum, 2016:53-54)

$\underline{9}$ El destacado es nuestro

10 Alejandro Bunge, en 1921 no hablaba del acompañamiento de la sociedad en general como aquí lo expresa Llach, pero si era consciente de que las transformaciones que intente llevar una nueva política necesitaba del acompañamiento de la “...opinión pública para que la Nación pueda cosechar cuanto antes el fruto de tan noble esfuerzo”. Conferencia pronunciada en el Instituto popular de Conferencias el 1-7-1921. Véase en Halperín Donghi, 2005:527.

\section{Bibliografía}

Bonaudo, Marta (Dir.). (1999) Nueva Historia Argentina. Liberalismo, estado y orden burgués (1852-1880). Tomo 4. Buenos Aires: Sudamericana.

Chiaramonte, José Carlos. (1971) Nacionalismo y liberalismo económicos en la Argentina, 18601880. Buenos Aires: Solar. 
Cortes Conde, Roberto. (1973) “Problemas de crecimiento industrial (1870-1914)” en Cortes Conde, Roberto y Gallo, Ezequiel. La formación de la Argentina Moderna. Buenos Aires: Paidós

Díaz Alejando, Carlos. (1975) Ensayos sobre la historia económica argentina. Buenos Aires: Amorrortu.

Dorfman, Adolfo. (1970) Historia de la industria argentina. Buenos Aires: Ediciones del Solar..

Dos Santos, Theotonio. (1975) "La crisis de la teoría del desarrollo y las relaciones de dependencia en América Latina” en AA. WW. La dependencia político-económica de América Latina. México: Siglo XXI.

Gallo, Ezequiel y Cortes Conde, Roberto. (1995) Historia Argentina. La república conservadora. Buenos Aires: Paidós.

Gallo, Ezequiel. (1998) "La expansión agraria y el desarrollo industrial en la Argentina (18801930)”. Anuario del IEHS. N¹3.

Gerchunoff, Pablo y Aguirre, Horacio. (2006) “Lo nuevo por nacer, lo viejo por morir: la economía argentina entre la gran guerra y la gran depresión”. Buenos Aires: CEPAL.

Gerchunoff, Pablo y Fajgelbaum, Pablo (2016) ¿Por qué Argentina no fue Australia Historia de una obsesión por lo que no fuimos, ni somos, pero... ¿seremos?. Buenos Aires: Siglo XXI

Halperín Donghi, Tulio. (2005).Vida y Muerte de la República verdadera (1910-1930). Buenos Aires: Ariel.

Hora, Roy. (2010) Historia económica de la Argentina en el siglo XIX. Buenos Aires: Siglo XXI.

Jáuregui, Aníbal E. (1993) “El despegue de los industriales argentinos” en Ansaldi, Wando; Pucciarelli Alfredo R. y Villarruel, José C. (ed.). Argentina en la paz de dos guerras, 1914-1945. Buenos Aires: Biblos.

Korol, Juan Carlos y Sábato, Hilda (1997) La industrialización trunca: Una obsesión argentina. La Plata: Universidad Nacional de La Plata. Recuperado de: http://www.memoria.fahce.unlp.edu.ar/library?a=d\&c=arti\&d=Jpr2634

Llach, Juan. (1985). Alejandro Bunge. La Argentina que no fue. Tomo 1. Buenos Aires: IDES. Recuperado de: http://ides.org.ar/wp-content/uploads/2012/05/1 Llach.pdf

Rocchi, Fernando. (1998) "El imperio del pragmatismo: intereses, ideas e imágenes en la política industrial del orden conservador". Anuario IEHS. № 13.

Sábato, Jorge F. (1991) La clase dominante en la Argentina moderna. Formación y características. Buenos Aires: Imago Mundi. 